04,07,08

\title{
Влияние валентного состояния ионов Се на фазовую стабильность и механические свойства кристаллов твердых растворов
} на основе $\mathrm{ZrO}_{2}$

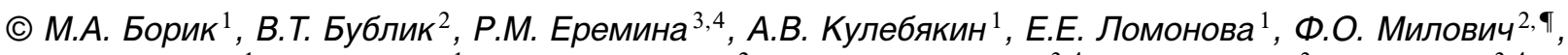 \\ В.А. Мызина ${ }^{1}$, В.В. Осико ${ }^{1}$, Н.Ю. Табачкова ${ }^{2}$, И.И. Фазлижанов ${ }^{3,4}$, В.А. Шустов ${ }^{3}$, И.В. Яцык ${ }^{3,4}$ \\ ${ }^{1}$ Институт общей фризики им. А.М. Прохорова РАН, \\ Москва, Россия \\ ${ }^{2}$ Национальный исследовательский технологический университет „МИСиС“, \\ Москва, Россия \\ ${ }^{3}$ Казанский физико-технический институт им. Е.К. Завойского КазНЦ РАН, \\ Казань, Россия \\ ${ }^{4}$ Казанский (Приволжский) фредеральный университет, \\ Казань, Россия \\ `E-mail: philippmilovich@gmail.com
}

(Поступила в Редакцию 29 марта 2017 г.)

\begin{abstract}
Проведено исследование структуры и механических свойств кристаллов твердых растворов диоксида циркония, стабилизированных оксидами иттрия и церия. Для идентификации ионов $\mathrm{Ce}^{3+}$ и их относительного количества в кристаллах использовали метод электронного парамагнитного резонанса. Показано, что основным фактором, определяющим высокое значение трещиностойкости кристаллов, является присутствие в них ионов $\mathrm{Ce}^{3+}$. Проведенные в работе отжиги, приводящие к уменьшению концентрации ионов $\mathrm{Ce}^{3+}$ подтверждают, что при изменении валентного состояния ионов церия значения трещиностойкости кристаллов уменьшаются.
\end{abstract}

Работа выполнена при поддержке гранта РФФИ № 16-02-00742 А, и № 15-38-70053 мол_а_мос.

DOI: 10.21883/FTT.2017.10.44958.101

\section{1. Введение}

Материалы на основе диоксида циркония, стабилизированные оксидом иттрия, вызывают большой интерес, поскольку они обладают рядом уникальных свойств: большой стойкостью к абразивному износу и низким коэффициентом трения, повышенной стойкостью к кислотам и щелочам. Одним из таких материалов является частично стабилизированный диоксид циркония (ЧСЦ). Деградация механических характеристик при высоких температурах (до $1400^{\circ} \mathrm{C}$ ) [1] в окислительных средах у кристаллов ЧСЦ существенно меньше, чем у металлов и конструкционной керамики. Химическая и биологическая инертность, прочность и высокая трещинностойкость делают кристаллы ЧСЦ перспективными для использования в медицине и технике $[2,3]$.

Материалы на основе диоксида циркония, в основном керамические, известны давно. Синтез кристаллических материалов с применением методов кристаллизации расплава [4] позволяет получать высокоплотные монолитные материалы с нулевой пористостью и отсутствием зеренной структуры. Поэтому кристаллы ЧСЦ обладают более высокими трибологическими и прочностными свойствами по сравнению с известными конструкционными керамическими материалами на основе $\mathrm{ZrO}_{2}$.

На фазовый состав, структуру и, в конечном итоге, на механические свойства ЧСЦ влияют такие параметры, как концентрация и вид стабилизирующего оксида, которые определяют концентрацию кислородных вакансий, а также технологические условия синтеза.

Исследование материалов на основе диоксида циркония, стабилизированные оксидом церия представляет большой интерес в связи с тем, что они характеризуются высокими значениями трещиностойкости - от 17 [5] до $35 \mathrm{MPa} \cdot \mathrm{m}^{1 / 2}[6]$.

Однако эти материалы по прочностным характеристикам, таким как микротвердость, модуль Юнга, прочность на изгиб, уступают материалам на основе диоксида циркония, стабилизированным оксидом иттрия. Одним из методов оптимизации механических характеристик материала является введение нескольких стабилизирующих оксидов, в частности, солегирование оксидами иттрия и церия. Так, в работах [7-9] изучали механические свойства керамических материалов на основе диоксида циркония, солегированных $\mathrm{Y}_{2} \mathrm{O}_{3}$ и $\mathrm{CeO}_{2}$ в зависимости от состава, зеренной структуры и условий синтеза.

Результаты исследования механических свойств кристаллов ЧСЦ, солегированных оксидами иттрия и церия приведены в работах $[10,11]$. Так, в работе [10] на единичном образце кристалла ЧСЦ (химический состав которого не приводится) были получены значения микротвердости $\left(H_{V}\right)$ и трещиностойкости $\left(K_{1 c}\right)$, которые составляли $(14.00-14.45) \mathrm{GPa}$ и $11.43 \mathrm{MPa} \cdot \mathrm{m}^{1 / 2}$ соответственно. Отмечалось также, что отжиг исходных 
образцов на воздухе приводит к незначительному увеличению $H_{V}$ до $14.81 \mathrm{GPa}$. Изучение влияния введения оксида церия в концентрациях до $1.0 \mathrm{wt} . \%$ в кристаллах ЧСЦ, стабилизированных $2.8 \mathrm{~mol} \% \mathrm{Y}_{2} \mathrm{O}_{3}$ методом кинетического микроиндентирования показало, что такое солегирование приводит к увеличению кинетической твердости, кинетического модуля Юнга и пластичности кристаллов и, таким образом, позволяет повысить их механические характеристики [11].

Целью настоящей работы является выяснение механизма влияния ионов церия на механические свойства твердого раствора на основе $\mathrm{ZrO}_{2}$ стабилизированного совместно $\mathrm{Y}_{2} \mathrm{O}_{3}$ и $\mathrm{CeO}_{2}$.

\section{2. Методика эксперимента}

Монокристаллы твердых растворов были выращены направленной кристаллизацией расплава в холодном контейнере. Рост кристаллов осуществлялся на установке „Кристалл-407“ в холодном контейнере диаметром $130 \mathrm{~mm}$ при скорости роста $10 \mathrm{~mm} / \mathrm{h}$. Вес наплавленного материала составлял 4-5 kg, скорость кристаллизации $10 \mathrm{~mm} / \mathrm{h}$, скорость охлаждения слитка закристаллизованного расплава от температуры расплава $\left(\sim 3000^{\circ} \mathrm{C}\right)$ до $1000^{\circ} \mathrm{C}$ составляла от 180 до $2000^{\circ} \mathrm{C} / \mathrm{min}$, а далее до комнатной температуры от 180 до $250^{\circ} \mathrm{C} / \mathrm{min}$. Были получены кристаллы твердых растворов на основе $\mathrm{ZrO}_{2}$ двух составов с общей концентрацией стабилизирующих оксидов иттрия и церия $2.8 \mathrm{~mol} \%$. Ниже приведены составы кристаллов и соответствующие им обозначения - 97.2 mol.\% $\mathrm{ZrO}_{2}-2.7 \mathrm{~mol} . \% \mathrm{Y}_{2} \mathrm{O}_{3}-0.1 \mathrm{~mol} . \% \mathrm{CeO}_{2}-$ 2.7Y0.1CeZr;

- 97.2 mol. $\% \mathrm{ZrO}_{2}-2.0 \mathrm{~mol} . \% \mathrm{Y}_{2} \mathrm{O}_{3}-0.8 \mathrm{~mol} . \% \mathrm{CeO}_{2}-$ 2.0Y0.8CeZr.

Для приготовления шихты использовались порошки оксидов циркония и скандия с содержанием основного вещества не менее $99.99 \%$. Отжиг кристаллов проводили при температуре $1200^{\circ} \mathrm{C}$ в течение 4 h на воздухе.

Фазовый анализ проводили методом рентгеновской дифрактометрии на установке Bruker D8, при использовании $\mathrm{CuK}_{\alpha}$ излучения. Структуру кристаллов исследовали методом просвечивающей электронной микроскопии с помощью микроскопа JEM 2100 фирмы JEOL, при ускоряющем напряжении $200 \mathrm{kV}$. Для утонения образца использовали ионное травление на установке PIPS II.

Для идентификации ионов $\mathrm{Ce}^{3+}$ и их относительного количества в кристаллах использовали метод электронного парамагнитного резонанса (ЭПР). Температурную зависимость спектров ЭПР измеряли на спектрометре фирмы Bruker ER 200 SRC (EMX/plus) с проточным криостатом фирмы Oxford Instruments ESR900 Temperature Controller ITC 503s в интервале температур от $5 \mathrm{~K}$ до $80 \mathrm{~K}$ в $X-(v=9.3 \mathrm{GHz})$ и $Q$-диапазоне $(v=37.4 \mathrm{GHz})$. Измерения спектров ЭПР при температуре $4.2 \mathrm{~K}$ выполнены на спектрометре Varian-E-12.
Исследования микротвердости кристаллов ЧСЦ проводили на микротвердомере Виккерса 402MVD Instron Wolpert Wilson Instruments c максимальной нагрузкой $2 \mathrm{~kg}$. Трещиностойкость измеряли методом индентирования на приборе Wolpert Hardness Tester930 с минимальной нагрузкой $5 \mathrm{~kg}$. Величину трещиностойкости $\left(K_{1 c}\right)$ рассчитывали по формуле, приведенной в работе $[12]$

$$
K_{1 c}=0.035(L / a)^{-1 / 2}(C E / H)^{2 / 5} H a^{1 / 2} C^{-1},
$$

где $K_{1 c}-$ коэффициент интенсивности напряжений $\left(\mathrm{MPa} \cdot \mathrm{m}^{1 / 2}\right) ; L$ - длина радиальной трещины $(\mathrm{m})$; $a$ - полуширина отпечатка $(\mathrm{m}) ; C$ - коэффициент Пуассона; $E$ - модуль Юнга (Рa); $H$ - микротвердость $(\mathrm{Pa})$.

\section{3. Результаты и обсуждение}

3.1. Измерение микротвердости и трещиностойкости кристаллов. Измерения микротвердости и трещиностойкости (критический коэффициент интенсивности напряжения $K_{1 c}$ ) образцов проводили методом индентирования. На рис. 1 приведено изображение отпечатков при разных нагрузках. Измерения значений трещиностойкости для кристаллов 2.7Y0.1CeZr проводили при нагрузке $5 \mathrm{~kg}$ (рис. 1, a), а для кристаллов 2.0Y0.8CeZr при нагрузке $20 \mathrm{~kg}$ (рис. $2, b$ ), так как только при этой нагрузке на индентор появлялись трещины вокруг отпечатка.

В табл. 1 приведены значения микротвердости и трещиностойкости кристаллов $2.7 \mathrm{Y0} 0.1 \mathrm{CeZr}$ и $2.0 \mathrm{Y} 0.8 \mathrm{CeZr}$ до и после отжига.

Как видно из табл. 1 отжиг кристаллов практически не влияет на значение микротвердости. Микротвердость кристалла 2.7Y0.1CeZr, с большим содержанием оксида иттрия, немного выше, чем кристалла 2.0Y0.8CeZr. При этом значения трещиностойкости у исследуемых кристаллов отличаются существенно. До отжига значение трещиностойкости кристалла $2.0 \mathrm{Y} 0.8 \mathrm{CeZr}$ почти в два

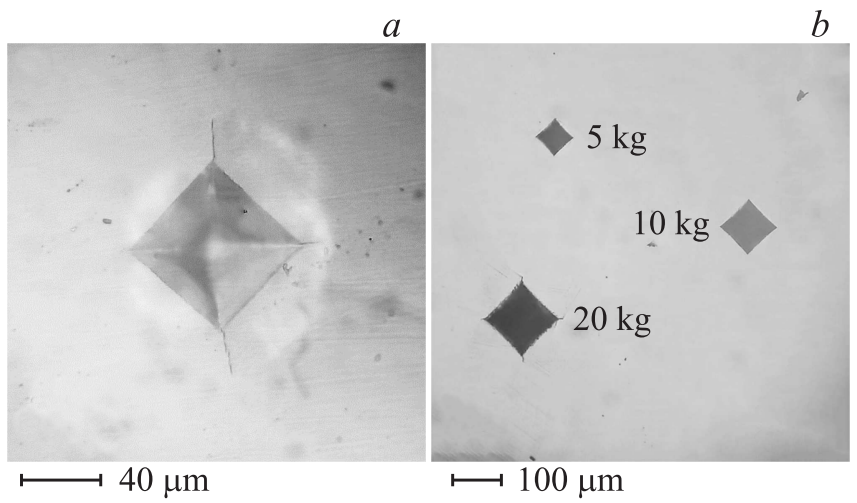

Рис. 1. Изображение отпечатков для кристалла $2.7 \mathrm{Y0} 0.1 \mathrm{CeZr}$ при нагрузке $5 \mathrm{~kg}(a)$ и отпечатков для кристалла $2.0 \mathrm{Y0} 0.8 \mathrm{CeZr}$ при разных нагрузках $(b)$. 
Таблица 1. Трещиностойкость и микротвердость кристаллов ЧСЦ до и после отжига

\begin{tabular}{c|c|c|c|c}
\hline \multirow{2}{*}{ Образец } & \multicolumn{2}{|c|}{ Микротвердость, $\mathrm{kgf} / \mathrm{mm}^{2}$} & \multicolumn{2}{c}{ Трещиностойкость $\left(K_{1 c}\right), \mathrm{MPa} \cdot \mathrm{m}^{1 / 2}$} \\
\cline { 2 - 5 } & до отжига & после отжига & до отжига & после отжига \\
\hline $2.7 \mathrm{Y0.1CeZr}$ & $1360 \pm 40$ & $1350 \pm 40$ & $13 \pm 0.6$ & $11 \pm 0.6$ \\
$2.0 \mathrm{Y0.8CeZr}$ & $1270 \pm 40$ & $1290 \pm 40$ & $25 \pm 0.6$ & $16 \pm 0.6$
\end{tabular}

Таблица 2. Фазовый состав кристаллов до и после отжига

\begin{tabular}{c|c|c|c|c|c|c}
\hline \multirow{2}{*}{ Образец } & \multicolumn{3}{|c|}{ До отжига } & \multicolumn{3}{c}{ После отжига } \\
\cline { 2 - 7 } & $\begin{array}{c}\text { Фазовый } \\
\text { состав }\end{array}$ & $c / \sqrt{ } 2 a$ & $\begin{array}{c}\text { Объемная } \\
\text { доля фаз, } \%\end{array}$ & $\begin{array}{c}\text { Фазовый } \\
\text { состав }\end{array}$ & \multicolumn{2}{c}{$\begin{array}{c}\text { Объемная } \\
\text { доля фаз, \% }\end{array}$} \\
\hline \multirow{2}{*}{$2.7 \mathrm{Y0} 0.1 \mathrm{CeZr}$} & $t-\mathrm{ZrO}_{2}$ & 1.016 & $86 \pm 5$ & $t-\mathrm{ZrO}_{2}$ & 1.016 & $85 \pm 5$ \\
& $t^{\prime}-\mathrm{ZrO}_{2}$ & 1.006 & $14 \pm 5$ & $t^{\prime}-\mathrm{ZrO}_{2}$ & 1.006 & $15 \pm 5$ \\
\hline $2.0 \mathrm{Y0.8CeZr}$ & $t-\mathrm{ZrO}_{2}$ & 1.017 & $90 \pm 5$ & $t-\mathrm{ZrO}_{2}$ & 1.016 & $83 \pm 5$ \\
& $t^{\prime}-\mathrm{ZrO}_{2}$ & 1.006 & $10 \pm 5$ & $t^{\prime}-\mathrm{ZrO}_{2}$ & 1.006 & $14 \pm 5$ \\
& & & $m-\mathrm{ZrO}_{2}$ & & $7 \pm 2$ &
\end{tabular}

* $t$ - тетрагональная модификация $\mathrm{ZrO}_{2}, m-$ моноклинная модификация $\mathrm{ZrO}_{2}$

раза выше, чем у кристалла 2.7Y0.1CeZr. После отжига значение трещиностойкости кристалла $2.7 \mathrm{Y} 0.1 \mathrm{CeZr}$ уменьшается и становится сопоставимым со значением трещиностойкости кристаллов стабилизированных только оксидом иттрия $\mathrm{ZrO}_{2}-2.8 \mathrm{~mol} . \% \mathrm{Y}_{2} \mathrm{O}_{3}$ [13]. Значение трещиностойкости для кристалла $2.0 \mathrm{Y} 0.8 \mathrm{CeZr}$ после отжига также уменьшается, но по-прежнему остается достаточно высоким.

3.2. Исследование фазового состава и структуры кристаллов. Одним из основных механизмов упрочнения в кристаллах ЧСЦ является фазовая мартенситная трансформация, когда напряжения, возникающие на острие микротрещины индуцируют тетрагонально-моноклинный переход, который поглощает энергию напряжений и блокирует дальнейшее продвижение микротрещины, в конечном итоге останавливая ее. Для оценки количества тетрагональной фазы ответственной за трансформационный механизм упрочнения был проведен фазовый анализ, результаты которого приведены в табл. 2.

Фазовый анализ показал, что в кристаллах до отжига есть две тетрагональные фазы с разной степенью тетрагональности $(c / \sqrt{ } 2 a)$. Тетрагональная фаза $(t)$, с соотношением $c / \sqrt{ } 2 a=1.016-1.017$ является „трансформируемой“, т.е. при приложении механической нагрузки может испытывать тетрагонально-моноклинное фазовое превращение и которая ответственна за трансформационное упрочнение в материалах на основе диоксида циркония [14]. Другая тетрагональная фаза $\left(t^{\prime}\right)$ с соотношением $c / \sqrt{ } 2 a=1.006$ „нетрансформируемая“ и даже под воздействием механической нагрузки при интенсивном размоле образца не будет испытывать тетрагонально-моноклинного перехода. Как видно из табл. 2, количество $(t)$ фазы ответственной за трансформационный механизм упрочнения в исследуемых кристаллах приблизительно одинаковое. После отжига в кристалле 2.0Y0.8CeZr появилось незначительное количество моноклинной фазы, а в кристалле $2.7 \mathrm{Y0.1CeZr}$ изменений фазового состава не наблюдали.

Детальное прямое исследование структуры кристаллов было проведено методом просвечивающей электронной микроскопии. На рис. 2 приведены светлопольные

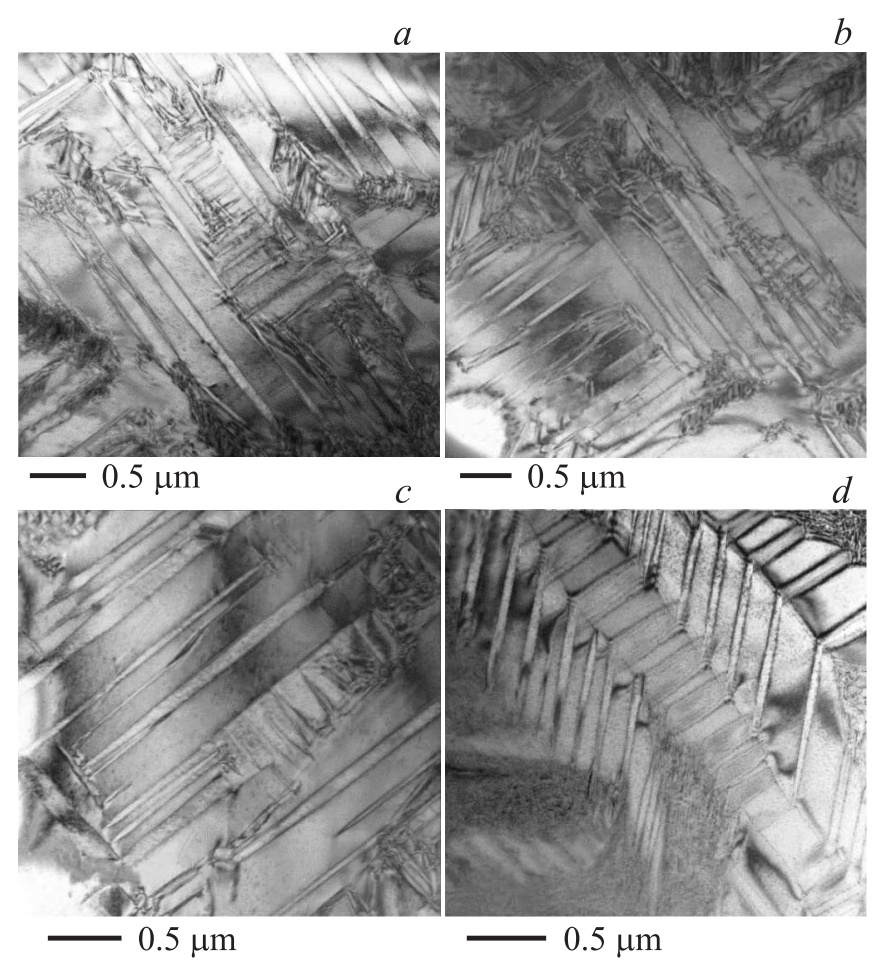

Рис. 2. ПЭМ изображения кристаллов: $a-2.7 \mathrm{Y} 0.1 \mathrm{CeZr}$ (до отжига), $b-2.7 \mathrm{Y} 0.1 \mathrm{CeZr}$ (после отжига), $c-2.0 \mathrm{Y0} 0.8 \mathrm{CeZr}$ (до отжига), $d-2.0 \mathrm{Y} 0.8 \mathrm{CeZr}$ (после отжига). 
изображения структуры кристаллов до и после отжига. Кристаллы обладали развитой двойниковой структурой, причем размеры и габитус двойников в кристаллах 2.0Y0.8CeZr и 2.7Y0.1CeZr не отличались. Отжиг кристаллов так же не привел к существенным изменениям дисперсности и морфологии двойниковой структуры.

Таким образом, результаты исследования фазового состава и двойниковой структуры кристаллов не позволяют объяснить существенную разницу в значениях трещиностойкости у кристаллов $2.0 \mathrm{Y} 0.8 \mathrm{CeZr}$ и $2.7 \mathrm{Y} 0.1 \mathrm{CeZr}$, a также изменение значений трещиностойкости в этих кристаллах после отжига.

3.3. Исследование кристаллов методом электронного парамагнитного резонанса. Спектры ЭПР кристаллов 2.7Y0.1CeZr и 2.0Y0.8CeZr до отжига были похожи. На спектрах присутствовали две линии от парамагнитных центров $\mathrm{Ce}^{3+}$, с формой, характерной для первой производной, с одинако-

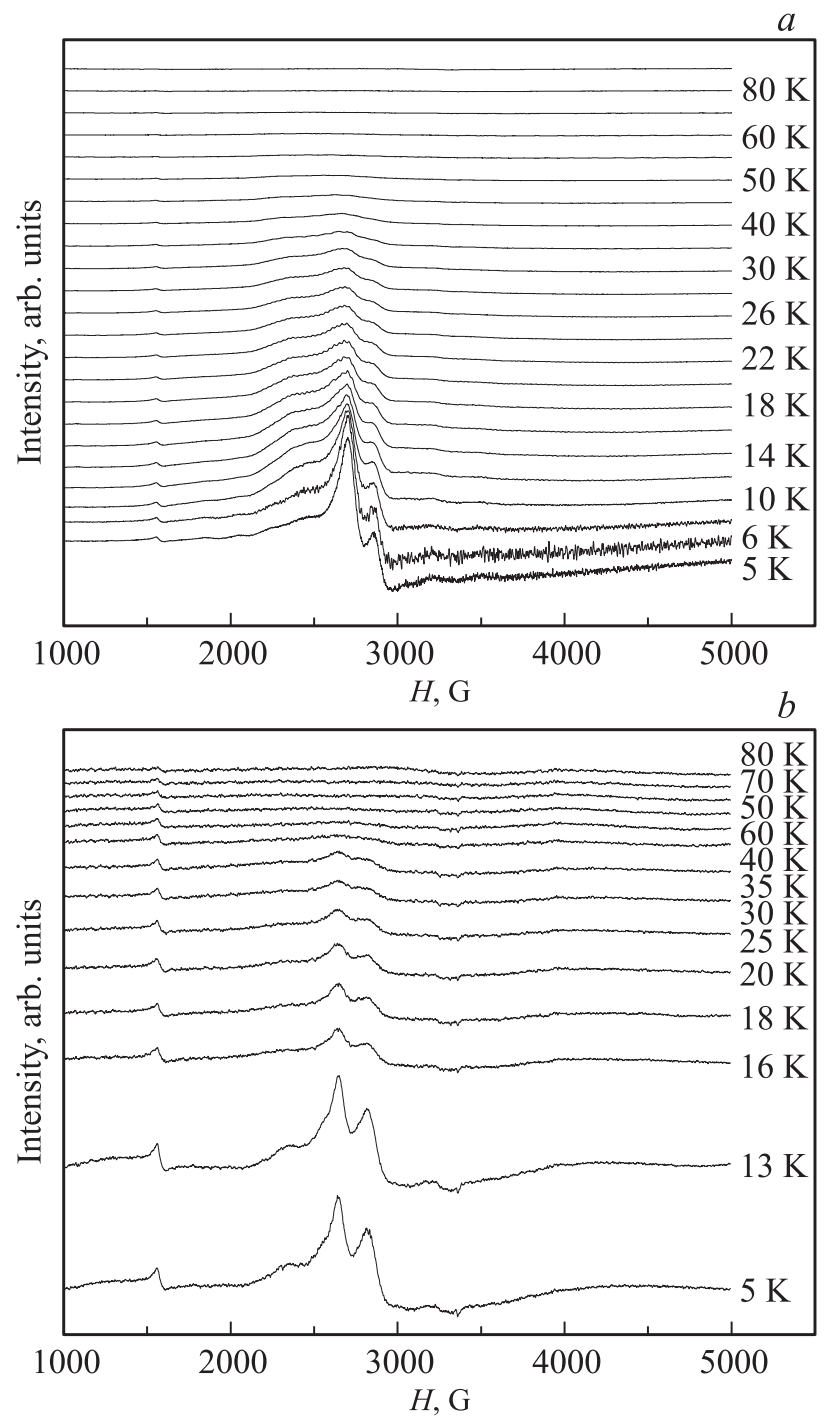

Рис. 3. Вид температурной зависимости спектров ЭПР в кристалле $2.0 \mathrm{Y} 0.8 \mathrm{CeZr}$ до $(a)$ и после отжига $(b)$.

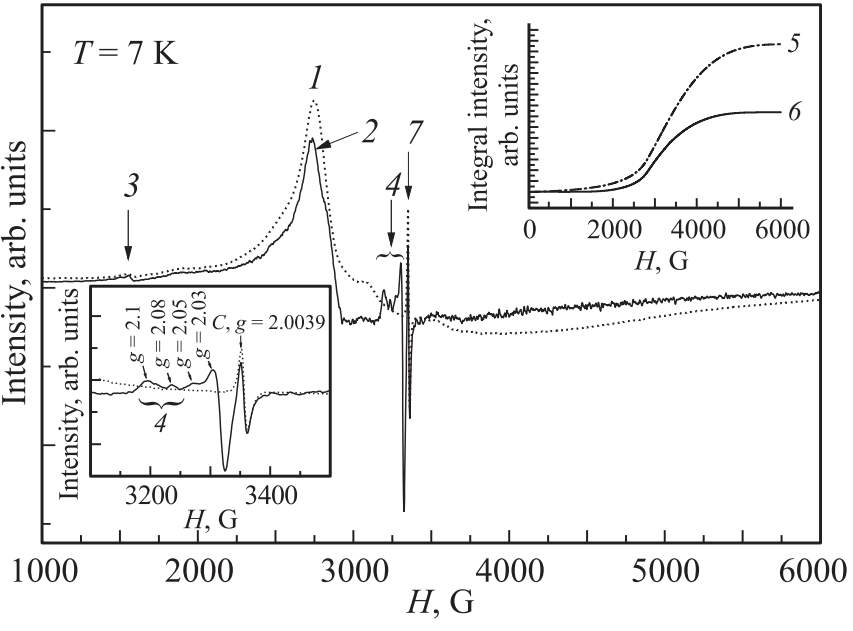

Рис. 4. Спектр ЭПР кристалла 2.0Y0.8CeZr при температуре $7 \mathrm{~K}$ до (1) и после (2) отжига. На вставке слева участок спектра ЭПР с рассчитанными $g$ факторами, принадлежащими к $\mathrm{O}^{-}$центрам (4). На вставке справа - интегральная интенсивность пиков спектра ЭПР ионов $\mathrm{Ce}^{3+}$ до (5) и после (6) отжига. (3) - центры $\mathrm{Fe}^{3+} ;$ (7) - центры эталона.

вой шириной и с небольшой угловой зависимостью, $g(\mathrm{I})_{1}=2.352, g(\mathrm{I})_{2}=2.531 \quad[15]$. Ион $\mathrm{Ce}^{4+}$ является немагнитным и в спектрах ЭПР не регистрируется. На рис. 3 приведена температурная зависимость спектров ЭПР для кристалла 2.0Y0.8CeZr до и после отжига. Линии ЭПР наблюдаются в диапазоне магнитных полей от 2000 до $3000 \mathrm{G}$ относятся к парамагнитным центрам $\mathrm{Ce}^{3+}$. Как видно из рис. 3 положение линий ЭПР не зависит от температуры, с повышением температуры интенсивность линий уменьшается и, при температурах выше 35 К линии ЭПР практически не наблюдаются, что характерно для иона церия $\mathrm{Ce}^{3+}[15]$.

После отжига в кристалле $2.7 \mathrm{Y0.1CeZr}$ сигналов от парамагнитных центров $\mathrm{Ce}^{3+}$ зарегистрировано не было. Очевидно, что в процессе отжига кристалла на воздухе, парамагнитные центры $\mathrm{Ce}^{3+}$ полностью окислились до состояний $\mathrm{Ce}^{4+}$. В кристалле $2.0 \mathrm{Y} 0.8 \mathrm{CeZr}$ после отжига присутствовали линии от парамагнитных центров $\mathrm{Ce}^{3+}$, но интегральная интенсивность спектра ЭПР уменьшилась. Кроме линий от парамагнитных центров $\mathrm{Ce}^{3+}$ на спектрах от кристалла 2.0Y0.8CeZr после отжига присутствовали еще две линии - $1550 \mathrm{G}$ и $3190 \mathrm{G}$. Первая линия $(1550 \mathrm{G})$ относится к катионам $\mathrm{Fe}^{3+}[16,17]$. Оксид железа, как неконтролируемая примесь в количестве $\sim 2 \cdot 10^{-5}$ wt.\% присутствовал в исходной шихте, а отжиг кристаллов на воздухе привел к окислению катионов железа до парамагнитного состояния $\mathrm{Fe}^{3+}$. Вторая дополнительная линия $(3190 \mathrm{G})$ принадлежит к $\mathrm{O}^{-}$центрам с орторомбической $\mathrm{C}_{2 v}$ симметрией $[16,18,19]$.

Для оценки концентрации ионов $\mathrm{Ce}^{3+}$ в кристалле 2.0Y0.8CeZr до и после отжига были зарегистрированы спектры ЭПР в присутствии эталона при температуpe $7 \mathrm{~K}$ (рис. 4). В качестве эталона использовали дре- 


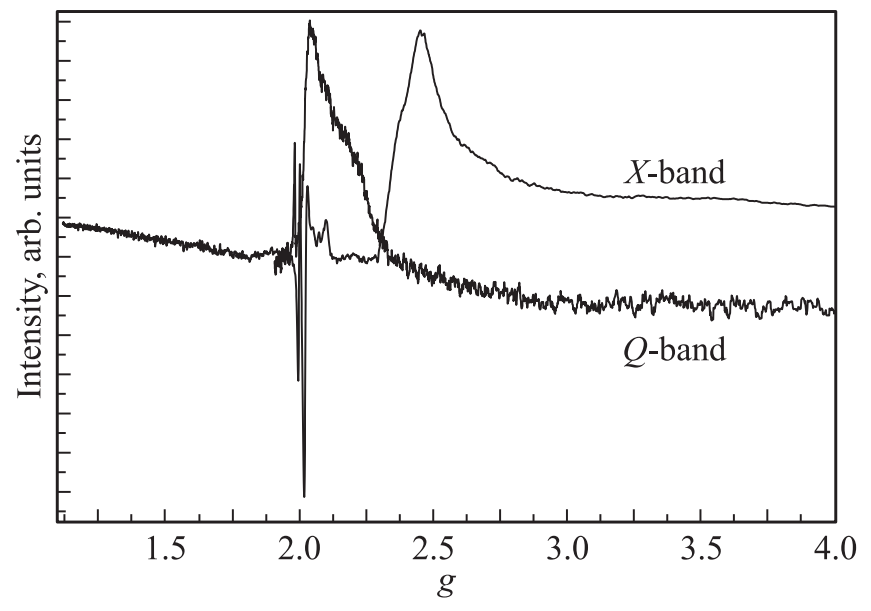

Рис. 5. Вид спектра ЭПР кристалла 2.0Y0.8CeZr после отжига в $Q$ - и $X$-диапазонах.

весный уголь. Отношение интегральных интенсивностей пиков спектра ЭПР парамагнитных центров ионов $\mathrm{Ce}^{3+}$ до и после отжига составило 1.86. Таким образом, после отжига на воздухе количество ионов $\mathrm{Ce}^{3+}$ в кристалле 2.0Y0.8CeZr уменьшилось почти в 2 раза.

На вставке слева (рис. 4) более подробно приведен участок спектра ЭПР с $g>g_{e}=2.0023$ от 2.03 до $2.1 \mathrm{c}$ линиями, принадлежащими к $\mathrm{O}^{-}$центрам. Данные центры наблюдали только в кристаллах после отжига, что согласуется с данными полученными в работах $[18,19]$.

На рис. 5 приведен спектр ЭПР кристалла 2.0Y0.8CeZr после отжига при температуре $4.2 \mathrm{~K}$ зарегистрированный в $X$ - и $Q$-диапазонах ( $X$-диапазон $v=9.3 \mathrm{GHz}$, $Q$-диапазон $v=37.4 \mathrm{GHz}$, по оси абсцисс отложены значения эффективного $g$-фактора).

Как видно из рис. 5, значения эффективных $g$-факторов линий магнитного резонанса $X$ - и $Q$-диапазонах не совпадают, так линии с $g \sim 2.35 ; g \sim 2.45$ наблюдаются в $X$-диапазоне, а в $Q$-диапазоне линии наблюдаются для эффективных $g$-факторов от 2 до 2.25 . Наиболее вероятной причиной таких особенностей спектра является то, что линии с $g \sim 2.35 ; g \sim 2.45$ относятся к кластерам, образованным парамагнитными центрами церия, связанными сильными обменными взаимодействиями. Угловая зависимость от приложенного внешнего магнитного поля практически не наблюдается для данных линий. Вероятной причиной отсутствия угловой зависимости является то, что примесные редкоземельные ионы расположены рядом друг с другом, образуя примесные кластеры с эффективным спином $S_{\text {eff }}=1 / 2$.

Таким образом, с помощью ЭПР однозначно показано, что в ростовых кристаллах присутствуют ионы $\mathrm{Ce}^{3+}$. После отжига на воздухе концентрация ионов $\mathrm{Ce}^{3+}$ уменьшается за счет перехода их в состояние $\mathrm{Ce}^{4+}$. В кристалле 2.7Y0.1CeZr происходит полное окисление, а в кристалле 2.0Y0.8CeZr после отжига часть ионов церия остается в состоянии $\mathrm{Ce}^{3+}$. Показано, что ионы
$\mathrm{Ce}^{3+}$ образуют кластеры. Наличие сильного обменного взаимодействия между ионами $\mathrm{Ce}^{3+}$ не позволяет определить локальное окружение ионов $\mathrm{Ce}^{3+}$, т.е. его распределение между моноклинной и тетрагональными фазами.

\section{4. Заключение}

В работе проведено исследование структуры и механических свойств кристаллов твердых растворов диоксида циркония, стабилизированных оксидами иттрия и церия. Наблюдаемое незначительное изменение фазового состава и двойниковой структуры кристаллов не позволяют объяснить существенную разницу в значениях трещиностойкости у кристаллов $2.0 \mathrm{YO} 0.8 \mathrm{CeZr}$ и $2.7 \mathrm{Y0} 0.1 \mathrm{CeZr}$, а также изменение значений трещиностойкости в этих кристаллах после отжига.

Показано, что основным фактором, определяющим высокое значение трещиностойкости кристаллов, является присутствие в них ионов $\mathrm{Ce}^{3+}$, причем значение трещиностойкости увеличивается с увеличением концентрации оксида церия. После отжига на воздухе концентрация ионов $\mathrm{Ce}^{3+}$ уменьшается, что приводит к уменьшению значений трещиностойкости. При полном окислении ионов $\mathrm{Ce}^{3+}$ до состояния $\mathrm{Ce}^{4+}$ в кристалле 2.7Y0.1CeZr значение трещиностойкости соответствует значению трещиностойкости в кристаллах диоксида циркония, стабилизированных только оксидом иттрия.

Мы полагаем, что высокая трещиностойкость кристаллов, легированных ионами церия связана с кристаллохимическими особенностями структуры. Поскольку размер ионного радиуса $\mathrm{Ce}^{3+}$ значительно превосходит ионный радиус $\mathrm{Ce}^{4+}$, то его присутствие в кристаллической решетке твердого раствора вызывает ее более сильное искажение. При переходе $\mathrm{Ce}^{3+} \rightarrow \mathrm{Ce}^{4+}$ происходит релаксация упругих напряжений, что, вероятно, и является причиной высокой трещиностойкости кристаллов твердых растворов диоксида циркония, легированных оксидом церия.

\section{Список литературы}

[1] C.J. Chan, F.F. Lange, M. Ruhle, J.F. Jue, A.V. Virkar. J. Am. Ceram. Soc. 74, 807 (1991).

[2] J. Chevalier, L. Gremillard, A.V. Virkar, D.R. Clarke. J. Am. Ceram. Soc. 92, 1901 (2009).

[3] I. Denry, J.R. Kelly. Dental Mater. 24, 299 (2008).

[4] V.V. Osiko, M.A. Borik, E.E. Lomonova. Springer Handbook of crystal growth. (2010). P. 432.

[5] R.H.J. Hannink, P.M. Kelly, B.C. Muddle. J. Am. Ceram. Soc. 83, 461 (2000).

[6] K. Tsukuma. Ceramics Bull. 65, 1386 (1986).

[7] M.M.R. Boutz, A.J.A. Winnubst, B.V. Langerak, R.J.M. Olde Scholtenhuis, K. Kreuwel, A.J. Burggraaf. J. Mater. Sci. 30, 1854 (1995).

[8] M. Turon-Vinasa, J.J. Roaa, F.G. Marro, M. Anglada. Ceram. Int. 41, 14988 (2015). 
[9] R. Maurya, A. Gupta, S. Omar, K. Balani. Ceram. Int. 42, 11393 (2016).

[10] G.A. Gogotsi, S.N. Dub, B.I. Ozerskii, D.Yu. Ostrovoi, G.E. Khomenko, E.E. Lomonova, S.Kh. Batygov, M.A. Vishnyakova, V.F. Kalabukhova, S.V. Lavrishchev, V.A. Myzina. Refractories 36, 199 (1995).

[11] В.В. Алисин, М.А. Борик, А.В. Кулебякин, Е.Е. Ломонова, В.А. Мызина, О.А. Нелюбова, Н.Ю. Табачкова, О.Н. Чурляева. Неорган. материалы 51, 609 (2015).

[12] K. Niihara, R. Morena, D.P.H. Hasselman. J. Mater. Sci. Lett. 1, 13 (1982).

[13] M.A. Borik, V.T. Bublik, A.V. Kulebyakin, E.E. Lomonova, F.O. Milovich, V.A. Myzina, V.V. Osiko, S.V. Seryakov, N.Y. Tabachkova. J. Eur. Ceram. Soc. 35, 1889 (2015).

[14] I. Yamashita, K. Tsukuma. J. Am. Cer. Soc. 91, 1634 (2008).

[15] С.А. Альтшулер, Е.М. Козырев. Электроный парамагнитный резонанс соединений элементов промежуточных групп. Наука, М. (1972). 672 с.

[16] J. Matta, J. Lamonier, E. Abi-Aad, E.A. Zhilinskaya, A. Abouka. Phys. Chem. Chem. Phys. 1, 4975(1999)

[17] K. Sasaki. J. Maier. Solid State Ionics 134, 303 (2000).

[18] J. Costantini, F. Beuneu, S.M. Smith, R. Devanathan, W.J. Weber. J. Appl. Phys. 110, 123506 (2011).

[19] J. Costantini, F. Beuneu, K. Schwartz, C. Trautmann. J. Phys.: Cond. Matter 22, 315402 (2010). 